\title{
Importance of Lactic Acid in Maintaining Vaginal Health: A Review of Vaginitis and Vaginosis Etiopathogenic Bases and a Proposal for a New Treatment
}

\author{
Javier Haya1, Africa García1, Carlos López-Manzanara1, Maher Balawi1, Lara Haya² \\ ${ }^{1}$ General University Hospital of Ciudad Real, College of Medicine, University of Castilla-La Mancha, Ciudad Real, Spain \\ ${ }^{2}$ College of Medicine, Autonomous University of Madrid, Madrid, Spain \\ Email: haya.javier@gmail.com
}

Received 1 July 2014; revised 1 August 2014; accepted 29 August 2014

Copyright (C) 2014 by authors and Scientific Research Publishing Inc.

This work is licensed under the Creative Commons Attribution International License (CC BY).

http://creativecommons.org/licenses/by/4.0/

c) (i) Open Access

\section{Abstract}

The most frequent cause of visits to the gynecologist in the western world is vaginal discomfort (vaginitis and vaginosis) whose origin lies in the uncontrolled proliferation of bacteria, such as haemophilus vaginalis or Candida-type fungi, normally considered as saprophytes. Such uncontrolled development of saprophytes is caused by some types of aggression against Döderlein bacilli and/or by a significant decrease in the amount of lactic acid (use of broad-spectrum antibiotics, douches with aggressive products, etc.). Consequently, as the vagina creates a progressively alkalinized and increasingly inadequate environment for the lactobacilli activity, a more favorable environment for the growth of saprophytes is created. The more alkaline the medium becomes, the lower the production of lactic acid. Therefore a vicious circle is created, resulting in the bacillus acidophilus near the lack of metabolism and the disappearance of lactic acid, hydrogen peroxide and bacteriocins. All of the above make it possible for saprophytic bacteria to proliferate and become pathogenic. So far, all vaginitis and vaginosis treatments have solely been focused on attacking the disproportionately developed bacteria but have not addressed the restoration of a vaginal acidic environment, i.e. the environment allowing the proliferation of lactic acid-producing bacillus acidophilus. This explains the high rate of relapse occurring after the treatment of these vaginal profiles. In this paper we propose a new treatment focused on the use of lactic acid to prevent recurrence after a vaginitis or vaginosis treatment.

\section{Keywords}

Vaginal Health, Vaginitis, Vaginosis, Lactic Acid 


\section{Introduction}

The vagina is an organ greatly important to women as it is a source of pleasure, but also a source of potential pain. It is open to the outside, and located near the anus, where the number of potentially pathogenic bacteria is large. Therefore a vaginal protection system is needed to prevent the proliferation of pathogens in the body. Although this protection system already exists, vaginal discomfort is the most frequent cause for visiting gynecologists. This article makes a point to explain the reason why these pathological profiles obviously occur because of a vaginal protection system malfunctioning. However, it would be convenient to bring forward some main ideas that will make the reading and understanding of the full article easier.

The vaginal protection system is based on the maintenance of a 3.5 to 4.5 acidic $\mathrm{pH}$ where the common and potentially pathogenic saprophytes do not find the favorable conditions to proliferate, whereas acidophilus bacilli are in their ideal environment. In these circumstances, acidophilus bacilli highly metabolize and produce large amounts of lactic acid by glucose anaerobic fermentation. Lactic acid keeps its acidic $\mathrm{pH}$, thus creating a virtuous circle that prevents the uncontrolled growth of other bacteria present in the vagina.

The origin of vaginitis and vaginosis lies in the breaking of the "acidic $\mathrm{pH}$-acidophilic bacteria high metabol-

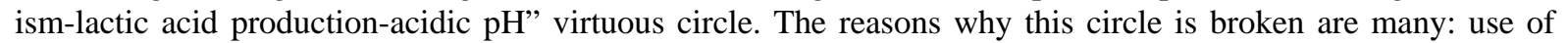
broad-spectrum antibiotics, inadequate douches, long periods, etc. and the consequences are the following: vagina alkalization, slowing down of acidophilus bacilli metabolism, and decrease in lactic acid production. A vicious circle is created, where the usually harmless vaginal saprophytic bacteria find an appropriate medium to proliferate and where vaginitis or vaginosis typical profiles are triggered.

While the vaginal physiology has been widely studied, and the knowledge has been widely spread in the medical community, it has not been taken into account in the vaginitis and vaginosis treatments for unclear reasons. So far clinicians have only used medicines to treat the overgrowth of symptoms-producing pathogen-converted saprophytes without taking into account the restoration of the physiological vaginal ecosystem. This would explain why the recurrence rate in both clinical profiles is so high.

This article deepens in the description of the vaginal physiological defense mechanism against pathogenic development and in the proposal of a new way to treat vaginal discomfort, based not only on reducing the number of vaginal pathogens, but also in restoring the acidic $\mathrm{pH}$, thus creating a favorable environment for acidophilus bacilli to recover the virtuous circle that maintains vaginal health. Achieving the acidic medium after treating, the overgrowth of saprophytes-pathogens should be carried out by using a vaginal physiological molecule: lactic acid. Taking this into account, our proposal is that it would be necessary to provide lactic acid to the vagina after the common vaginitis or vaginosis have been treated, so that the vagina can quickly recover its acidic $\mathrm{pH}$ and therefore its acidophilus bacilli optimum growth conditions.

\section{Vagina and Vaginal Flora}

\section{General Aspects}

Although it is an internal organ, the vagina is not sterile, such as the pancreas or the heart, because of its connection with the exterior. In addition, because its opening is close to the anus, it is a place with a very high burden of potentially pathogenous intestinal bacteria. Therefore it is essential for the vagina to have a powerful yet simple and ingenious protection system to prevent from the disorderly and problem-causing proliferation of germs.

Protection against the pathogen growth is based on the presence of a large number of non-pathogenic saprophytic bacteria in the vagina, which avoid the presence of unwanted microorganisms [1]. These bacteria are generally known as Döderlein's bacillus_-in honor of Albert Gustav Döderlein Sigmund (1860-1941), who first described their presence in the vagina in 1892 (Figure 1).

Another common term to refer to these bacteria, considered as authentic guardians of vaginal health, is acidophilus bacilli, because they operate and proliferate better and develop more intensely in acid medium. These bacilli can generate a special acid medium of 3.5 to 4.5, which creates a virtuous circle that facilitates their growth but hinders the growth of other germs. Acidification is based on the production of lactic acid, the major subproduct generated after the glucose fermentation without oxygen.

Döderlein's bacilli are also often referred to as lactobacilli because of their property to ferment milk products, which results in the production of yogurt. These bacteria [2] are used together with Streptococcus thermophilus to industrially obtain the yogurts that can be found in any store. This explains why the odor of a healthy vagina 


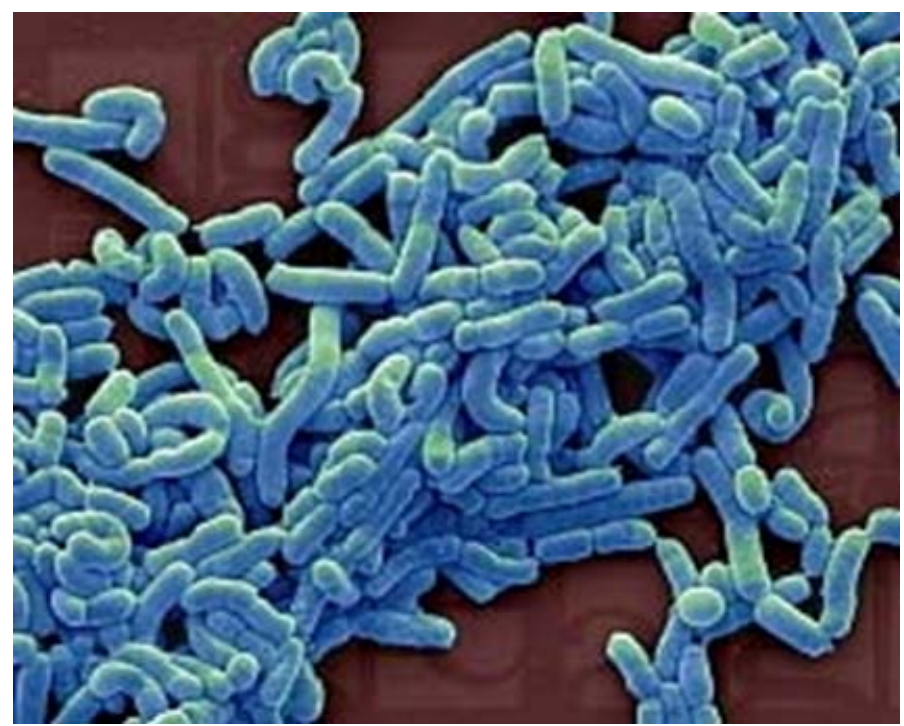

Figure 1. Vaginal Lactobacillus acidophilus or Döderlein bacillus.

is usually described as similar to the odor of yogurt. Also, at an empirical level, some yogurt has been occasionally introduced into vaginas to alleviate discomfort. After referring to the most frequent names of glucose-fermenting and lactic acid-producing saprophytic bacteria in the vagina, it seems convenient to determine the most appropriate name to designate them. In this respect, the general consensus is that "lactic acid bacteria" or "Lactobacillus acidophilus", often abbreviated as L. acidophilus are the most appropriate designations.

Since Döderlein's first description, lactobacilli have generally been considered as guardians of the vaginal ecosystem, the second most bacteria-populated place in the human being after the colon. Indeed their quantity is so high that 10,000 to 100 million lactobacilli can be found per gram of vaginal fluid [3].

All the microorganisms living in the vagina are known with the generic name of "vaginal microbiota" or simply "microbiota".

\section{Vaginal Microbiota}

\subsection{Lactobacillus acidophilus}

Although Döderlein thought that the bacteria he described belonged to only one single species, vaginal Lactobacillus acidophilus form a heterogeneous group of diverse bacterial species, which in turn may present various strains. Although more than 20 vaginal lactobacillus species have been identified, only 6 are really important to the vaginal ecosystem: L. crispatus, L. gasseri, L. iners, L. jensenii, L. vaginalis, L. buchneri [4]. The vaginal population is much more heterogeneous than previously thought. Indeed, species of Bacteroides, Staphylococcus epidermidis, Corynebacterium, Peptostreptococcus and Eubacterium and other bacterial species, such as Atopobium vaginae, Megasphera, Leptotrichia and Mycoplasma can be found in the vaginal microbiota of healthy women.

Interestingly, many of these lactic acid-producers bacteria, like lactobacilli, may be even more abundant in some healthy women and especially in colored and Hispanic women. This would mean that in order to maintain a healthy vagina what is really important is not the presence of acidophilus bacilli, but rather the existence of lactic acid and an acidic $\mathrm{pH}$.

These bacteria, commonly found in the vagina, have shown their capacity to inhibit the in vitro growth of various pathogenic microorganisms, such as Bacteroides fragilis, Escherichia coli, Gardnerella vaginalis, Mobiluncus spp., Neisseria gonorrhoeae, Peptostreptococcus anaerobius, and Staphylococcus aureus. It is generally accepted that this is achieved mainly through the action of lactic acid.

\subsection{Physiological Conditions of the Vagina. Role of Lactic Acid}

A low and acidic $\mathrm{pH}$ is generally considered as the primary mechanism for maintaining the composition of a 
healthy vaginal microflora. Indeed, most lactobacilli thrive best at a $\mathrm{pH}<4.5$, which clearly justifies its designations as "acidophilus" or lovers of acidity.

The characteristic $\mathrm{pH}$ of women of reproductive age, i.e. between 3.5 and 4.5, is achieved thanks to the presence of a sufficient amount of lactic acid in the vagina. Therefore this molecule is the key to maintaining a medium which favors the growth of lactobacilli in a vaginal environment.

As historical curiosities, it is known that the Swedish chemist Carl Wilhelm Scheele refined lactic acid from milk sour for the first time in 1780. In 1808, Jöns Jacob Berzelius discovered that muscles also produce lactic acid (actually L-lactate) during exercise. The chemical structure of lactic acid was established by Johannes Wislicenus in 1873. In 1856, Louis Pasteur discovered Lactobacillus and its role in the production of lactic acid, which was first commercially produced by the German company Boehringer Ingelheim in 1895.

In 2011, the world production of lactic acid reached 275,000 tons, with an average annual growth of $10 \%$. Lactic acid has multiple uses, included as a food preservative agent due to its powerful antibacterial action.

Lactic acid is synthesized in the vagina by Lactobacillus acidophilus, obtained from pyruvic acid, through a glucose fermentation mechanism. Its two isoforms, dextro and levo, seem to be of little importance from a biological point of view.

\section{Other Inhabitants of the Vagina}

Multiple bacterial and non-bacterial species, including Candida, Gardnerella or Actinomyces (especially in IUD carriers) are commonly found in healthy women without any symptoms. In any case, in the absence of symptoms, their presence should not be considered as pathological, and their casual finding (generally in cytology for the screening of uterine cervix cancer) should not be treated [5]. The development of symptoms which depend on the excessive proliferation of one or more of these organisms, result in the decrease in lactobacilli, which in turn causes the reduction or the disappearance of acid lactic and an increase in vaginal $\mathrm{pH}$ [6].

Thus, it should be understood that both bacterial and fungal vaginitis, and vaginosis are related to quantitative alterations in the composition of the vaginal microflora rather than to the appearance of germs usually not living in it [7]. Therefore, except for tricomoniasis, in no case should vaginitis be considered as a sexually transmitted disease, but as an endogenous imbalance in the proportion of common microorganisms living in the vagina, with a relative decrease in vaginal Lactobacillus acidophilus and lactic acid [8].

\section{Defense Mechanisms of the Vagina}

\subsection{General Description. Vaginal Acid pH}

The previous section tackled the large number and the variety of germs coexisting in the vagina. It also explained that the key for the maintenance of the vaginal health is the presence of lactic acid, which creates an acidic $\mathrm{pH}$, as well as the Lactobacillus acidophilus that produce such $\mathrm{pH}$. Obviously, some kind of instrument must be available so that women do not feel discomfort in their vagina.

The vagina inhibits the growth of pathogens through a mechanism that is striking because of its effectiveness and simplicity.

To summarize, the entire system pivots around lactic acid because lactic acid allows the maintenance of an acidic $\mathrm{pH}$ around 3.5 - 4.5 and it is not favorable for the growth of fungi, protozoa, Haemophilus and other unwanted bacteria, which generally need a pH greater than 6.0 [9]. On the contrary, lactobacilli are acidophilic, i.e. they feel comfortable in an acidic environment, which enables their maximal proliferation [10]. Lactic acid is produced and the physiological state of acidity is reached thanks to the following landmarks [11]:

- Ovaries produce estradiol.

- The multilayered epithelium of the vaginal mucosa proliferates thanks to estradiol, which also induces the glycogen loading of these cells.

- Vaginal epithelial cells gradually flake out in the vaginal lumen.

- Desquamated cells undergo a lytic process which allows the release of the glycogen contained in them.

- Glycogen is metabolized through acidophilus bacilli via anaerobic fermentation, i.e., without oxygen. The main "waste" product resulting from glucose anaerobic fermentation is lactic acid, which is, as mentioned, the cornerstone to acidify the vaginal environment (Figure 2). 


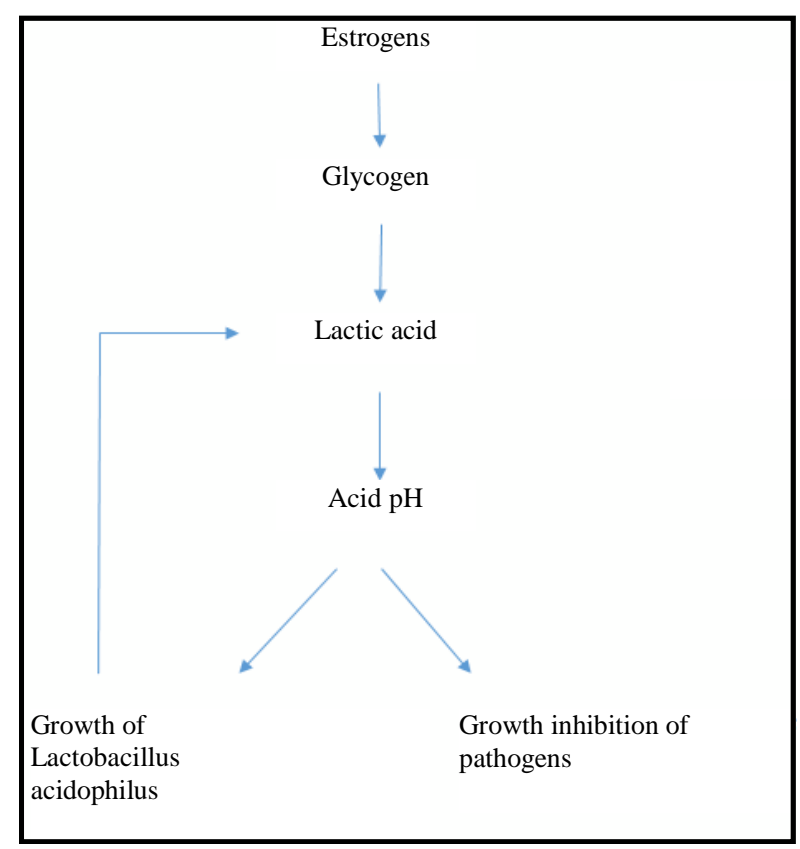

Figure 2. Virtuous circle produced in the vagina in physiological conditions.

Despite the presence of potential pathogens such as Candida [12], this is the essential mechanism explaining the maintenance of vaginal health.

However, the above mentioned mechanism is also complemented by other defense mechanisms, such as the production of hydrogen peroxide $\left(\mathrm{H}_{2} \mathrm{O}_{2}\right)$ and the production of bactericidal substances (bacteriocins) [13]. Although their origin lies in acidophilic bacteria, they need an acidic environment to show a proper metabolic activity, which implies the necessary presence of lactic acid. The complementary instruments to lactic acid and vaginal acidity are briefly described below.

\subsection{Hydrogen Peroxide $\left(\mathrm{H}_{2} \mathrm{O}_{2}\right)$}

In fact, the synthesis of hydrogen peroxide is also related to the presence of lactic acid [14] because the hydrogen ions of lactic acid react enzymatically with oxygen to produce hydrogen peroxide [15].

This product, widely used in the medical field as an effective disinfectant, has a negative impact on microbial species with no catalase enzyme, which destroys this molecule. Without this enzyme, the structure of germs is deeply harmed and they end up dying [16]. Logically, the catalase enzyme is part of Lactobacillus acidophilus, which makes them immune to hydrogen peroxide.

\subsection{Bacteriocins}

Vaginal lactobacilli produce several specific antimicrobial substances with a peptide structure. Such substances are referred to generically as "bacteriocins" [17]. Lactocin and Crispasin are two examples worth mentioning. Many studies have shown that a low $\mathrm{pH}$ favors the activity of bacteriocins. Therefore the presence of lactic acid is also somehow involved in the mechanism protecting vaginal health.

\section{Physiological Changes in the Vaginal Environment}

The vaginal ecosystem undergoes major compositional changes throughout a woman's life. From childhood until puberty, the limited presence of estrogens implies a low bacterial content in the vagina, which occurs during reproductive years. On the other hand, during menopause, as estrogen levels drop, not only the epithelial fragility of vaginal mucosa is affected, due to the decrease in the thickness of the different cellular layers, but also the vaginal flora due to the decrease of Lactobacillus acidophilus which depend on the presence of glycogen to sur- 
vive. Therefore the vagina loses much of its self- cleaning ability and natural defenses [18].

It is also worth outlining that several factors influence the balance of the vaginal microbiota in one way or another during the long period of a woman's reproductive life. The most important ones are being described below:

- Menstrual cycle: During menstruation, the vaginal environment is less acidic (pH 6 or more) because the menstrual blood drags the lactic acid present in the vagina. Furthermore, lactobacilli drop in number because they bind to the erythrocytes of menstrual blood instead of remaining in the epithelial cells that cover the vagina. Therefore menstruation becomes a risk factor for the maintenance of the vaginal ecosystem, which explains why many women often refer to nonspecific vaginal discomfort after their menstruation, which is secondary to the deficit of lactic acid and Lactobacillus acidophilus. These symptoms will persist as long as a woman is unable to recover the level of vaginal acidity before menstruation.

- Coition: As already outlined, the vaginal pH of reproductive women ranges from 3.5 to 4.5. However, sperm has been shown to act as a powerful alkalizing agent which reduces vaginal acidity within a few seconds and keeps the vagina neutralized (to a pH higher than 6 - 7) during several hours after intercourse, when spermatozoa can enter into the female reproductive organs [19]. Due to the neutralization of the vagina acidity, sperm, which poorly tolerates the usual acidity of the vagina, gets protected and pathogens, finding the alkaline suitable for colonization, can also take advantage of it. Therefore, because of the presence of semen in the vagina, natural protective mechanisms are neutralized. This can explain that many women suffer from vaginal discomfort after periods of frequent sex relations due to the alteration of the vaginal microbiota rather than to friction mechanical factors.

- Hormonal contraceptives: The use of contraceptives with very low or no levels of etinilestradiol causes a state of relative hipoestrogenemia, which disrupts the production of glycogen, and therefore of lactic acid. Consequently, these women are particularly susceptible to alterations of the vaginal ecosystem [20] with resulting discomfort.

- Breastfeeding: During breastfeeding the amount of estrogens is relatively low because the ovaries need a few weeks to recover their full functionality. Therefore the situation is similar to the case of low-dose estrogen hormonal contraceptives.

\section{Pathological Changes of the Vaginal Ecosystem}

Various circumstances can pathologically contribute to the destruction of the physiological vaginal ecosystem, favoring the proliferation of pathogens and vaginal symptoms, such as vaginitis or vaginosis. The most common ones are being outlined below:

- Use of intravaginal products: Such as showers with antiseptic or soap products, which deeply alter the vaginal ecosystem, as they drag lactic acid and Lactobacillus acidophilus which help reach a non-acidic $\mathrm{pH}$. Although this problem can be especially emphasized if alkali products are used for douchings these are not a requisite for the vaginal ecosystem to be altered, as too frequent hygiene (more than twice a day) is sufficient to modify the conditions of the vagina.

- Use of antibiotics: The action of antibiotics not only destroys pathogenic organisms but also causes a decrease in the "good microorganisms" of our body's natural flora. Lactobacilli acidophilus, as well as much of the intestinal flora, are sensitive to broad-spectrum antibiotics, especially beta-lactams. For instance, the use of systemic antibiotics can justify the appearance of more or less severe diarrhea. Similarly, it justifies vaginitis caused by Candida as fungi are not susceptible to antibiotics and they are therefore not affected by them, whereas Lactobacillus acidophilus are. In fact, before starting an antibacterial treatment in women of reproductive age, all physicians should know that the binomial "antibiotic treatment—Candida vaginitis" is very frequent.

- Chronic stress: Chronic stress favors the production of large amounts of steroids, mainly cortisol, which in turn have a negative impact on multiple systemic structures. The vagina is one of these structures, i.e. it is a place also reached by adrenal corticosteroids, which alter the growth of Lactobacillus acidophilus and the production of lactic acid [21].

\section{Importance of Lactic Acid}

Since the discovery of lactic acid, Lactobacillus acidophilus have been considered as "the guardians of the va- 
gina” [22] and lactic acid has clearly shown to be its main "weapon” [23]. Indeed, although little attention has been paid to this molecule, lactic acid is the key for the maintenance of the health of the vagina, because it creates an acidic $\mathrm{pH}$ which favors the development of acidophilus bacillus and inhibits the growth of pathogens (Figure 3).

As mentioned above, besides lactobacilli, the multiple microorganisms which can be found in the vagina in normal conditions, such as Gram-negative bacteria, Gram-positive bacteria and fungi, should not be a matter of concern. Indeed these are not dangerous for a vagina as long as the lactic acid and a low $\mathrm{pH}$ (lower than 4.5) are kept as they need an alkaline medium or a low acidic medium to get reproduced [24].

As already mentioned in this study, lactic acid can be considered as the angular stone in the normal maintenance of the vaginal ecosystem [25]. Its presence in adequate amounts ensures the maintenance of an acid vaginal $\mathrm{pH}$, where bacilli can adequately proliferate and correctly metabolize. Furthermore, the lactic acid compound produces hydrogen peroxide and also favors the action of bacteriocins, lethal for a broad number of pathogens. Therefore, the absence of lactic acid consequently increases $\mathrm{pH}$ and creates an aggressive medium for acidophilus bacilli which develop badly in a non-acidic medium [26]. In addition, hydrogen peroxide disappears and the amount of bacteriocins and their capacity to act decreases. Consequently, vaginal well-being depends upon lactic acid, which is considered as a real vaginal disinfectant [27].

Although it has long been thought that the main potential of lactic acid is focused on its antibacterial solution, recent studies have also proven its antiviral effect, including the HIV [28] and herpes viruses [29].

The pathophysiology of almost all vaginitis is based on the existence of some type of attack on Döderlein bacilli and/or a significant decrease in lactic acid [30], which causes the progressive alkalization of the vagina and creates an increasingly inappropriate medium for the lactobacilli activity. The more alkaline the medium becomes, the lower the production of lactic acid. All this triggers the creation of a vicious circle, since the metabolism of Lactobacillus acidophilus is almost held back and lactic acid, hydrogen peroxide and bacteriocins disappear, letting a free way for pathogens to proliferate [31]. The proliferation of pathogenic germs produces a wide range of vaginal symptoms, from mild nonspecific discomfort to intense itching, that have a deep impact on the quality of life of women (Figure 4).

\section{Vaginal Health Recovery: A Proposal for a New Treatment of Vaginitis and Vaginosis}

As mentioned, the proliferation of pathogens, and especially of Candida and Gardnerella, occurs when the delicate balance of the vaginal microbiota is broken and the amount of Lactobacillus acidophilus and lactic acid decrease, resulting in more or less severe symptomatic candidal vaginitis and bacterial vaginosis, respectively. However, the so-called "nonspecific vaginitis" also occurs when the determination of the causing agent in symptomatic women is not easy due to the proliferation of multiple pathogens and no clear predominance of any of them.

Taking the above into account, it is easily understandable that exogenous lactic acid leads to the acidification of the vagina, making it easier for Döderlein bacilli to regain their metabolic capacity. When this happens, a virtuous circle created by Döderlein bacilli begins. Indeed, these increase the production of lactic acid, which

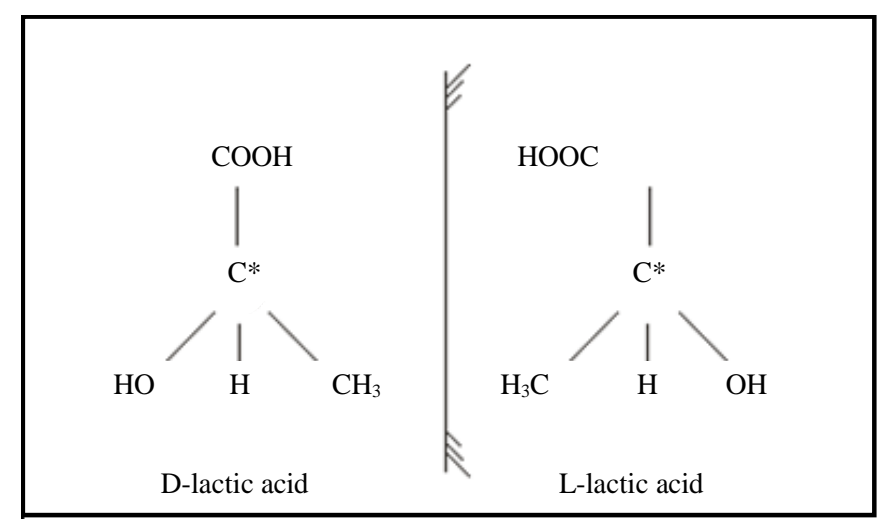

Figure 3. Chemical structure of lactic acid with its two isomers. 


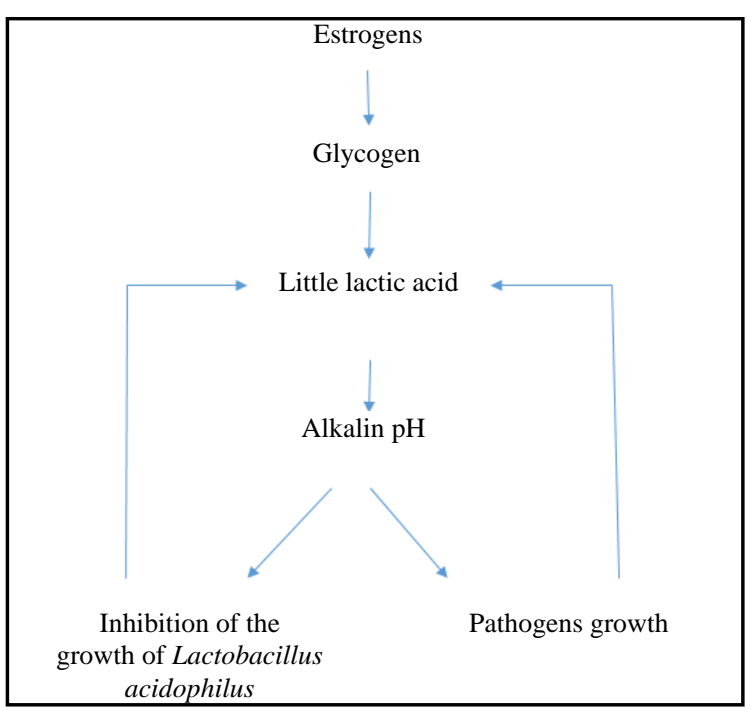

Figure 4. Vicious circle produced in vaginitis/vaginosis.

acidifies the vagina. Then, the existence lactic acid results in the appearance of bacteriocins and hydrogen peroxide, creating an adverse environment for the growth of pathogens, which number gets eventually drastically reduced. When this occurs, vaginal discomfort disappears.

Lastly, according to the ever increasing available information, lactic acid stimulates the immune system, which could contribute to maintaining vaginal health. However, the value of such property has generally received little recognition [32].

According to a wide range of studies, the frequency of these infections is so high that $100 \%$ of women will suffer from vaginitis/vaginosis at least once in their lives. However, the fact is that women commonly suffer from different symptoms during their lives. On the other hand, recurrent vaginitis or vaginosis are of a greater concern than isolated episodes since it is not uncommon for women to suffer from vaginal infections every month in spite of being apparently healed. Treating these infections can be sometimes exasperating, both for the clinician and the patient. Although it is frequent for the physician to prescribe multiple and varied treatmentstopical and systemic-, as well as the partner's treatment, the change in women's lifestyle, etc., recurrent infections do not cease and reappear periodically.

As the physiology of the vagina and what happens in it in case of vaginitis or vaginosis is better understood nowadays, it is much easier to prescribe a logical and rational treatment, which not only heals the patient in the first place (which is usually straightforward) but also, and more importantly, prevents and avoids relapse.

In a woman diagnosed with candidal vulvovaginitis, bacterial vaginosis or a nonspecific vaginitis, the treatment should be focused on two confluent aspects [33]:

- The decrease in the pathogen quantity.

- The recovery of the vaginal $\mathrm{pH}$.

In general, for most clinicians only the first part of the treatment is necessary, ie, the reduction or the elimination of pathogens [34]. Therefore, it is usual to prescribe topical imidazoles, generally clotrimazole (one single $500 \mathrm{mg}$ dosage, vaginal tablet) or a systemic triazole, such as fluconazole (one single $150 \mathrm{mg}$ dosage, capsule) for the treatment of fungi, and metronidazole or clindamycin in one of the many existing dosages for bacterial vaginosis and nonspecific vaginitis. The common factor of all these drugs is that they actively act on pathogens, but not on lactobacilli, which are not sensitive to them. These treatments are generally very effective since they drastically reduce the amount of pathogens, and therefore symptoms improve quickly.

As all the clinicians are aware of the risk of recurrent infections, many suggest a similar treatment for the woman's partner, according to the idea that the reason for symptom recurrence is the re-infection caused by the sexual partner, who would act as a reservoir. This is untrue because Candida cannot survive in the penis, unless the man has any predisposing disease. The same occurs with Gardenerella and other germs that cause nonspecific vaginitis.

As the vaginal $\mathrm{pH}$ must be recovered to actually prevent relapse, it is necessary to restore favorable conditions 
so that Lactobacillus acidophilus, which do really protect women from the recurrence of new infections, can proliferate and develop [35].

Therefore, probiotics have been recommended for quite a long time as adjunctive therapies to the use of fungicides or antibiotics [36]. The idea is good in itself, since they would enable the lactobacilli population's quick recovery. However, when reviewing the issue thoroughly, it is not the best to do it because [37]:

- The Lactobacillus acidophilus prescribed do not necessarily correspond to the woman's saprophytes [38]. Each woman's own flora may be different from other women's. Therefore it would be more appropriate to prescribe the Lactobacillus acidophilus species that best meets each patient's situation and which corresponds to her vaginal ecosystem [39].

- The development of Lactobacillus acidophilus will be precarious until the vagina has not achieved its acidification. Indeed, the vagina needs to previously reach an acidic $\mathrm{pH}$ for these germs to develop quickly. In case a critical mass of lactobacilli cannot be reached, the lactic acid production may be insufficient to obtain the acidic $\mathrm{pH}$ necessary for these bacteria to find the best proliferation conditions [40] [41]. However, it may be difficult to reach a sufficient number of Lactobacillus capable of producing a significant amount of lactic acid to acidify the vagina, and thus to favor their growth. We are faced to a vicious cycle.

Taking all the above into account, it may be logical to think that the first step to restore the normal vaginal physiology would be to quickly reach an acidic $\mathrm{pH}$ (below 4.5). However, if this cannot be achieved, then it seems unlikely to find the exogenous bacteria produced in the vaginal ecosystem. Thus, in the short or the long term, it would be possible for pathogens to develop, and a new symptomatic profile to appear [42].

How can a vaginal acidic $\mathrm{pH}$ be restored after pathogens have been removed or reduced? Lactic acid is the most physiological way and it is the authentic antiseptic as it ends up with bacteria, actually prevents the proliferation of pathogens and favors the growth of Lactobacillus acidophilus. By providing lactic acid to the vagina, the clinician avoids depending on the actions of the exogenous probiotics administered, thus eliminating a problematic step. As mentioned, as long as the amount of lactic acid and the acidic pH are insufficient, the environmental conditions will not favor the proliferation of saprophytic bacteria and their metabolic activity in the vagina.

\subsection{Main Advantages of the Direct Administration of Lactic Acid}

- The intervention of bacteria will not be required to achieve an acid pH quickly and safely.

- On the other hand, achieving an acidic $\mathrm{pH}$ during vaginitis or vaginosis would enable women's own bacteria and more specifically those still present in the vagina to proliferate, though in smaller amounts. This would not be the case of any other exogenous bacteria, which proper adaptability to the particular conditions of each woman cannot be ensured.

In conclusion (Figure 5), the ideal treatment of vaginitis or vaginosis consists of the administration of an antifungal or an antibiotic, as appropriate, to significantly reduce the amount of pathogens, and then quickly acidify the vagina with lactic acid [43].

Thanks to acidity, the growth of germs causing the symptoms will decrease, and the quick growth of Lactobacillus acidophilus specific to each woman will be possible. As already mentioned, more lactic acid will be produced and any symptomatic recurrence will be prevented [44].

It would be safer and more advisable to acidify the vagina as soon as possible after one or several menstrual periods through the administration of lactic acid at the end of the period.

\subsection{More Specifically, the Following Posology Could Be Established}

- Candidal vulvovaginitis: One single $500 \mathrm{mg}$ dosage of clotrimazole vaginal tablet or $150 \mathrm{mg}$ fluconazole in a capsule taken orally, followed by the topical administration of lactic acid for a week (one vaginal tablet in the morning and one in the evening, or only in the evening, depending on the virulence of symptoms). Lactic acid will be administered again after the end of the following menstrual period.

- Nonspecific vaginitis and bacterial vaginosis: Topical metronidazole or clindamycin for 3 to 5 days, twice daily. As indicated for candidal vulvovaginitis, such topical treatment will be followed by lactic acid in the same dosage as mentioned above. In this case, more important than the dose, which in any case will be enough as the topical administration reaches high concentrations, is the duration of the treatment which should never be shorter than three days. 


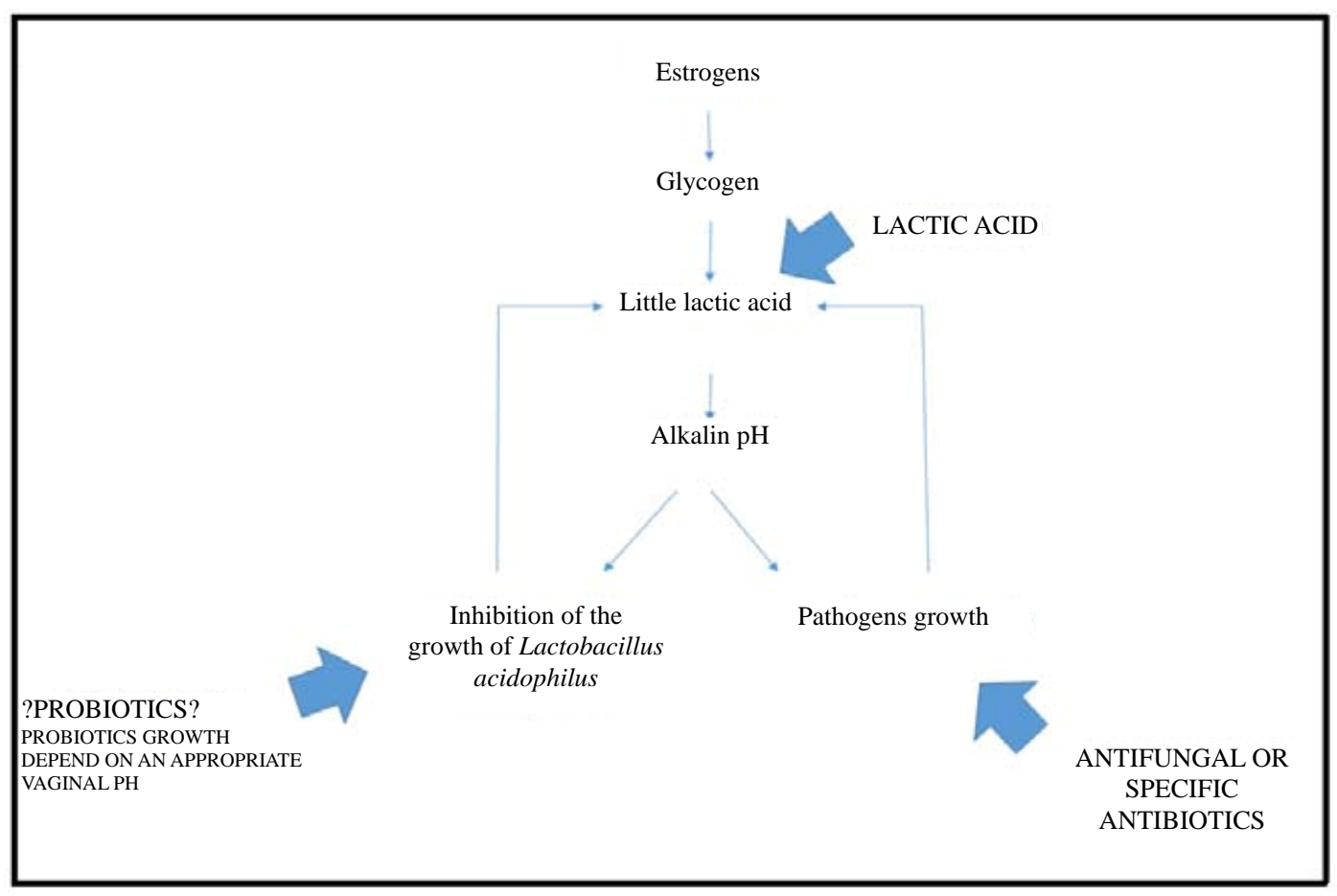

Figure 5. Ways to break the vicious cycle and prevent recurrence.

- Nonspecific discomfort of unclear origin: In this case the use of lactic acid may be more than enough to eliminate symptoms and normalize the vaginal ecosystem, allow the proliferation of Lactobacillus acidophilus and limit the metabolic activity of other vaginal germs. Studies with other organic acids which cause the acidification of the vagina have also shown good results in these cases.

It is also interesting to consider the protective role of lactic acid when a woman is treated with systemic antibiotics, which may alter the vaginal flora. It is frequent to use penicillin and its derivatives to which Lactobacillus acidophilus are very sensitive. It should not be forgotten that the lactobacilli population will in all likelihood be significantly reduced in the vagina, which parallelly will result in a decrease of vaginal lactic acid, and secondarily in an increase of the $\mathrm{pH}$, all of which may promote the proliferation of pathogens. Thus, it would be interesting to establish the practice to routinely add an intravaginal topical application of lactic acid in vaginal tablets to the oral or parenteral antibiotics, as it would help maintain the acidic $\mathrm{pH}$, prevent the growth of pathogen, and therefore the development of vaginitis or vaginosis clinical symptoms. Actually it would be something similar to what is done when Omeprazole is administered to patients that receive any treatment with NSAIDs. Lastly, it should be remembered that the topical administration of lactic acid in the vagina does not involve any risk because it is a natural and common substance of the vagina.

Until now, no treatment based only on lactic acid with a comfortable dosage for patients was available in Spain. However, currently, a national laboratory, "Arafarma Group, S.A.” has launched an innovative galenic product called Fisiolat which contains $250 \mathrm{mg}$ lactic acid and is precisely indicated for the prevention and/or the elimination of initial and recurrent vaginal infections. In an ongoing clinical study named "proposal of a new protocol for the treatment of vaginitis and vaginosis to prevent recurrence", the really satisfactory results obtained reaffirm the opinions of other authors.

\section{Conclusions}

1) In normal conditions, a large number of saprophytes can be found in the vagina, being the most important acidophilic bacteria which produce lactic acid.

2) Lactic acid keeps the vagina within an acidic $\mathrm{pH}$ between 3.5 and 4.5, which is the ideal environment for acidophilus bacilli to find a suitable medium to metabolize. This makes it possible for these bacteria to produce large amounts of lactic acid, which maintains an acidic $\mathrm{pH}$, and creates a virtuous circle. 
3) The origin of vaginitis and vaginosis lies in the alteration of the number of acidophilus bacilli and/or the alkalization of the vaginal $\mathrm{pH}$, allowing the proliferation of common vaginal saprophytes, which become pathogenic and produce symptoms. Therefore in no case should these profiles be considered as infections proceeding from the outside.

4) The treatment of vaginitis and vaginosis should deal not only with the reduction in the number of causing-symptoms pathogens, as done traditionally, but also with the primary objective to recover the vaginal $\mathrm{pH}$ and restore the virtuous circle that maintains a healthy vagina. Not doing so makes it easier for the clinical profiles of vaginosis and vaginitis to recur. This sometimes causes despair in women and their doctor.

5) The virtuous circle of recovery should be done through the application of lactic acid, which acidifies the medium, hinders the growth of vaginal saprophytes and promotes the proliferation of lactic acid-producing acidophilus bacilli.

6) Based on the above, our treatment approach is to use traditional medicines against saprophytes, i.e. the pathogens that cause vaginal symptoms, but use lactic acid afterwards, at least for a week, to ensure the normal vaginal ecosystem recovery.

\section{References}

[1] Vasquez, A., Jakobsson, T., Ahrne, S., Forsum, U. and Molin, G. (2002) Vaginal Lactobacillus Flora of Healthy Swedish Women. Journal of Clinical Microbiology, 40, 2746-2749. http://dx.doi.org/10.1128/JCM.40.8.2746-2749.2002

[2] Anjum, N., Maqsood, S., Masud, T., Ahmad, A., Sohail, A. and Momin, A. (2014) Lactobacillus acidophilus: Characterization of the Species and Application in Food Production. Critical Reviews in Food Science and Nutrition, 54, 1241-1251. http://dx.doi.org/10.1080/10408398.2011.621169

[3] Ravel, J., Gajer, P., Abdo, Z., Schneider, G.M., Koenig, S.S., McCulle, S.L., Karlebach, S., Gorle, R., Russell, J., Tacket, C.O., Brotman, R.M., Davis, C.C., Ault, K., Peralta, L. and Forney, L.J. (2011) Vaginal Microbiome of Reproductive-Age Women. Proceedings of the National Academy of Sciences USA, 108, 4680-4687. http://dx.doi.org/10.1073/pnas.1002611107

[4] Pendharkar, S., Magopane, T., Larsson, P.G., De Bruyn, G., Gray, G.E., Hammarström, L. and Marcotte, H. (2013) Identification and Characterisation of Vaginal Lactobacilli from South African Women. BMC Infectious Diseases, 13, 43. http://dx.doi.org/10.1186/1471-2334-13-43

[5] Atassi, F., Brassart, D., Grob, P., Graf, F. and Servin, A.L. (2006) Lactobacillus Strains Isolated from the Vaginal Microbiota of Healthy Women Inhibit Prevotella bivia and Gardnerella vaginalis in Coculture and Cell Culture. FEMS Immunology and Medical Microbiology, 48, 424-432. http://dx.doi.org/10.1111/j.1574-695X.2006.00162.x

[6] Garg, K.B., Ganguli, I., Kriplani, A., Lohiya, N.K., Thulkar, J. and Talwar, G.P. (2010) Metabolic Properties of Lactobacilli in Women Experiencing Recurring Episodes of Bacterial Vaginosis with Vaginal $\mathrm{pH}>$ or $=5$. European Journal of Clinical Microbiology Infectious Diseases, 29, 123-125. http://dx.doi.org/10.1007/s10096-009-0818-1

[7] Brotman, R.M. (2011) Vaginal Microbiome and Sexually Transmitted Infections: An Epidemiologic Perspective. Journal of Clinical Investigation, 121, 4610-4617. http://dx.doi.org/10.1172/JCI57172

[8] Kaewsrichan, J., Peeyananjarassri, K. and Kongprasertkit, J. (2006) Selection and Identification of Anaerobic Lactobacilli Producing Inhibitory Compounds against Vaginal Pathogens. FEMS Immunology and Medical Microbiology, 48, 75-83. http://dx.doi.org/10.1111/j.1574-695X.2006.00124.x

[9] De Gregorio, P.R., Juárez Tomás, M.S., Santos, V. and Nader-Macías, M.E. (2012) Beneficial Lactobacilli: Effects on the Vaginal Tract in a Murine Experimental Model. Antonie van Leeuwenhoek, 102, 569-580. http://dx.doi.org/10.1007/s10482-012-9752-9

[10] Rönnqvist, P.D., Forsgren-Brusk, U.B. and Grahn-Håkansson, E.E. (2006) Lactobacilli in the Female Genital Tract in Relation to Other Genital Microbes and Vaginal pH. Acta Obstetricia et Gynecologica Scandinavica, 85, 726-735. http://dx.doi.org/10.1080/00016340600578357

[11] Boskey, E.R., Telsch, K.M., Whaley, K.J., Moench, T.R. and Cone, R.A. (1999) Acid Production by Vaginal Flora in Vitro Is Consistent with the Rate and Extent of Vaginal Acidification. Infection and Immunity, 67, 5170-5175.

[12] Yan, D.H., Lü, Z. and Su, J.R. (2009) Comparison of Main Lactobacillus Species between Healthy Women and Women with Bacterial Vaginosis. Chinese Medical Journal, 122, 2748-2751.

[13] Aroutcheva, A., Gariti, D., Simon, M., Shott, S., Faro, J., Simoes, J.A., Gurguis, A. and Faro, S. (2001) Defense Factors of Vaginal Lactobacilli. American Journal of Obstetrics Gynecology, 185, 375-379.

[14] Atassi, F. and Servin, A.L. (2010) Individual and Co-Operative Roles of Lactic Acid and Hydrogen Peroxide in the Killing Activity of Enteric Strain Lactobacillus johnsonii NCC933 and Vaginal Strain Lactobacillus gasseri KS120.1 against Enteric, Uropathogenic and Vaginosis-Associated Pathogens. FEMS Microbiology Letters, 304, 29-38. 
http://dx.doi.org/10.1111/j.1574-6968.2009.01887.x

[15] Angeles-López, M., Ramos, E.G.C. and Santiago, C.A. (2001) Hydrogen Peroxide Production and Resistance to Nonoxinol-9 in Lactobacillus spp. Isolated from the Vagina of Reproductive-Age Women. Revista Latinoamericana de Microbiología, 43, 171-176.

[16] Hillier, S.L., Krohn, M.A., Rabe, L.K., Klebanoff, S.J. and Eschenbach, D.A. (1993) The Normal Vaginal Flora, $\mathrm{H}_{2} \mathrm{O}_{2}-$ Producing Lactobacilli, and Bacterial Vaginosis in Pregnant Women. Clinical Infectious Diseases, 16, S273-S281.

[17] Aroutcheva, A.A., Simoes, J.A. and Faro, S. (2001) Antimicrobial Protein Produced by Vaginal Lactobacillus acidophilus That Inhibits Gardnerella vaginalis. Infectious Diseases in Obstetrics and Gynecology, 9, 33-39. http://dx.doi.org/10.1155/S1064744901000060

[18] Jaisamrarn, U., Triratanachat, S., Chaikittisilpa, S., Grob, P., Prasauskas, V. and Taechakraichana, N. (2013) UltraLow-Dose Estriol and Lactobacilli in the Local Treatment of Postmenopausal Vaginal Atrophy. Climacteric, 16, 347 355.

[19] O’Hanlon, D.E., Lanier, B.R., Moench, T.R. and Cone, R.A. (2010) Cervicovaginal Fluid and Semen Block the Microbicidal Activity of Hydrogen Peroxide Produced by Vaginal Lactobacilli. BMC Infectious Diseases, 10, 120. http://dx.doi.org/10.1186/1471-2334-10-120

[20] Güzel, A.B., Küçükgöz-Güleç, Ü., Aydin, M., Gümral, R., Kalkanci, A. and Ilkit, M. (2013) Candida Vaginitis during Contraceptive Use: The Influence of Methods, Antifungal Susceptibility and Virulence Patterns. Journal of Obstetrics \& Gynaecology, 33, 850-856. http://dx.doi.org/10.3109/01443615.2013.834306

[21] Borges, S., Silva, J. and Teixeira, P. (2014) The Role of Lactobacilli and Probiotics in Maintaining Vaginal Health. Archives of Gynecology and Obstetrics, 289, 479-489. http://dx.doi.org/10.1007/s00404-013-3064-9

[22] Boris, S. and Barbés, C. (2000) Role Played by Lactobacilli in Controlling the Population of Vaginal Pathogens. Microbes and Infection, 2, 543-546.

[23] Graver, M.A. and Wade, J.J. (2011) The Role of Acidification in the Inhibition of Neisseria gonorrhoeae by Vaginal Lactobacilli during Anaerobic Growth. Annals of Clinical Microbiology and Antimicrobials, 10, 8. http://dx.doi.org/10.1186/1476-0711-10-8

[24] Lepargneur, J.P. and Rousseau, V. (2002) Protective Role of the Doderleïnflora. Journal de Gynécologie Obstétrique et Biologie de la Reproduction (Paris), 31, 485-494.

[25] O’Hanlon, D.E., Moench, T.R. and Cone, R.A. (2013) Vaginal pH and Microbicidal Lactic Acid When Lactobacilli Dominate the Microbiota. PLoS One, 8, e80074. http://dx.doi.org/10.1371/journal.pone.0080074

[26] Nam, H., Whang, K. and Lee, Y. (2007) Analysis of Vaginal Lactic Acid Producing Bacteria in Healthy Women. Journal of Microbiology, 45, 515-520.

[27] Jin, L., Tao, L., Pavlova, S.I., So, J.S., Kiwanuka, N., Namukwaya, Z., Saberbein, B.A. and Wawer, M. (2007) Species Diversity and Relative Abundance of Vaginal Lactic Acid Bacteria from Women in Uganda and Korea. Journal of Applied Microbiology, 102, 1107-1115.

[28] Aldunate, M., Tyssen, D., Johnson, A., Zakir, T., Sonza, S., Moench, T., Cone, R. and Tachedjian, G. (2013) Vaginal Concentrations of Lactic Acid Potently Inactivate HIV. Journal of Antimicrobial Chemotherapy, 68, 2015-2025. http://dx.doi.org/10.1093/jac/dkt156

[29] Isaacs, C.E. and Xu, W. (2013) Heaflavin-3,3'-digallate and Lactic Acid Combinations Reduce Herpes Simplex Virus Infectivity. Antimicrobial Agents and Chemotherapy, 57, 3806-3814. http://dx.doi.org/10.1128/AAC.00659-13

[30] Otero, M.C., Morelli, L. and Nader-Macías, M.E. (2006) Probiotic Properties of Vaginal Lactic Acid Bacteria to Prevent Metritis in Cattle. Letters in Applied Microbiology, 43, 91-97. http://dx.doi.org/10.1111/j.1472-765X.2006.01914.x

[31] Pybus, V. and Onderdonk, A.B. (1999) Microbial Interactions in the Vaginal Ecosystem, with Emphasis on the Pathogenesis of Bacterial Vaginosis. Microbes and Infection, 1, 285-292.

[32] Witkin, S.S., Alvi, S., Bongiovanni, A.M., Linhares, I.M. and Ledger, W.J. (2011) Lactic Acid Stimulates Interleukin23 Production by Peripheral Blood Mononuclear Cells Exposed to Bacterial Lipopolysaccharide. FEMS Immunology \& Medical Microbiology, 61, 153-158. http://dx.doi.org/10.1111/j.1574-695X.2010.00757.x

[33] Donders, G.G., Zodzika, J. and Rezeberga, D. (2014) Treatment of Bacterial Vaginosis: What We Have and What We Miss. Expert Opinion on Pharmacotherapy, 15, 645-657. http://dx.doi.org/10.1517/14656566.2014.881800

[34] Ehrström, S., Daroczy, K., Rylander, E., Samuelsson, C., Johannesson, U., Anzén, B. and Påhlson, C. (2010) Lactic Acid Bacteria Colonization and Clinical Outcome after Probiotic Supplementation in Conventionally Treated Bacterial Vaginosis and Vulvovaginal Candidiasis. Microbes and Infection, 12, 691-699. http://dx.doi.org/10.1016/j.micinf.2010.04.010

[35] Schwebke, J.R., Muzny, C.A. and Josey, W.E. (2014) Role of Gadnerellavaginalis in the Pathogenesis of Bacterial Va- 
ginosis-A Conceptual Model. The Journal of Infectious Diseases, Published Online.

[36] Flagas, M., Betsi, G.I. and Athanasiou, S. (2007) Probiotics for the Treatment of Women with Bacterial Vaginosis. Clinical Microbiology and Infection, 13, 657-664.

[37] Donders, G.G., Desmyter, J. and Vereecken A. (1998) Vaginitis. The New England Journal of Medicine, 338, 15481549.

[38] Homayouni, A., Bastani, P., Ziyadi, S., Mohammad-Alizadeh-Charandabi, S., Ghalibaf, M., Mortazavian, A.M. and Mehrabany, E.V. (2014) Effects of Probiotics on the Recurrence of Bacterial Vaginosis: A Review. Journal of Lower Genital Tract Disease, 18, 79-86.

[39] McLean, N.W. and Rosenstein, I.J. (2000) Characterisation and Selection of a Lactobacillus Species to Re-Colonise the Vagina of Women with Recurrent Bacterial Vaginosis. Journal of Medical Microbiology, 49, 543-552.

[40] Delucchi, L., Fraga, M., Perelmuter, K., Cidade, E. and Zunino, P. (2008) Vaginal Lactic Acid Bacteria in Healthy and Ill Bitches and Evaluation of in Vitro Probiotic Activity of Selected Isolates. Canadian Veterinary Journal, 49, 991994.

[41] Charlier, C., Cretenet, M., Even, S. and Le Loir, Y. (2009) Interactions between Staphylococcus aureus and Lactic Acid Bacteria: An Old Story with New Perspectives. International Journal of Food Microbiology, 131, 30-39. http://dx.doi.org/10.1016/j.ijfoodmicro.2008.06.032

[42] Andersch, B., Lindell, D., Dahlén, I. and Brandberg, A. (1990) Bacterial Vaginosis and the Effect of Intermittent Prophylactic Treatment with an Acid Lactate Gel. Gynecologic and Obstetric Investigation, 30, 114-119. http://dx.doi.org/10.1159/000293230

[43] Linhares, I.M., Giraldo, P.C. and Baracat, E.C. (2010) New Findings about Vaginal Bacterial Flora. Revista da Associação Médica Brasileira, 56, 370-374.

[44] Bahamondes, M.V., Portugal, P.M., Brolazo, E.M., Simões, J.A. and Bahamondes, L. (2011) Use of a Lactic Acid plus Lactoserum Intimate Liquid Soap for External Hygiene in the Prevention of Bacterial Vaginosis Recurrence after Metronidazole Oral Treatment. Revista da Associação Médica Brasileira, 57, 415-420. http://dx.doi.org/10.1590/S0104-42302011000400015 
Scientific Research Publishing (SCIRP) is one of the largest Open Access journal publishers. It is currently publishing more than 200 open access, online, peer-reviewed journals covering a wide range of academic disciplines. SCIRP serves the worldwide academic communities and contributes to the progress and application of science with its publication.

Other selected journals from SCIRP are listed as below. Submit your manuscript to us via either submit@scirp.org or Online Submission Portal.
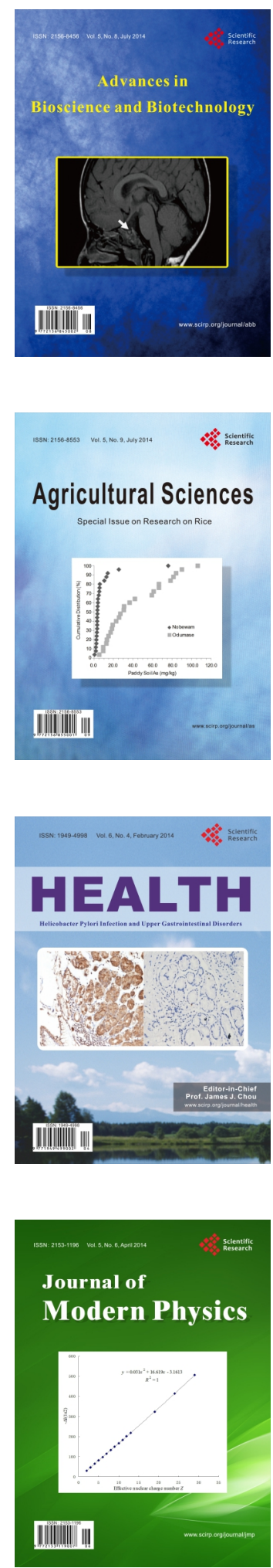
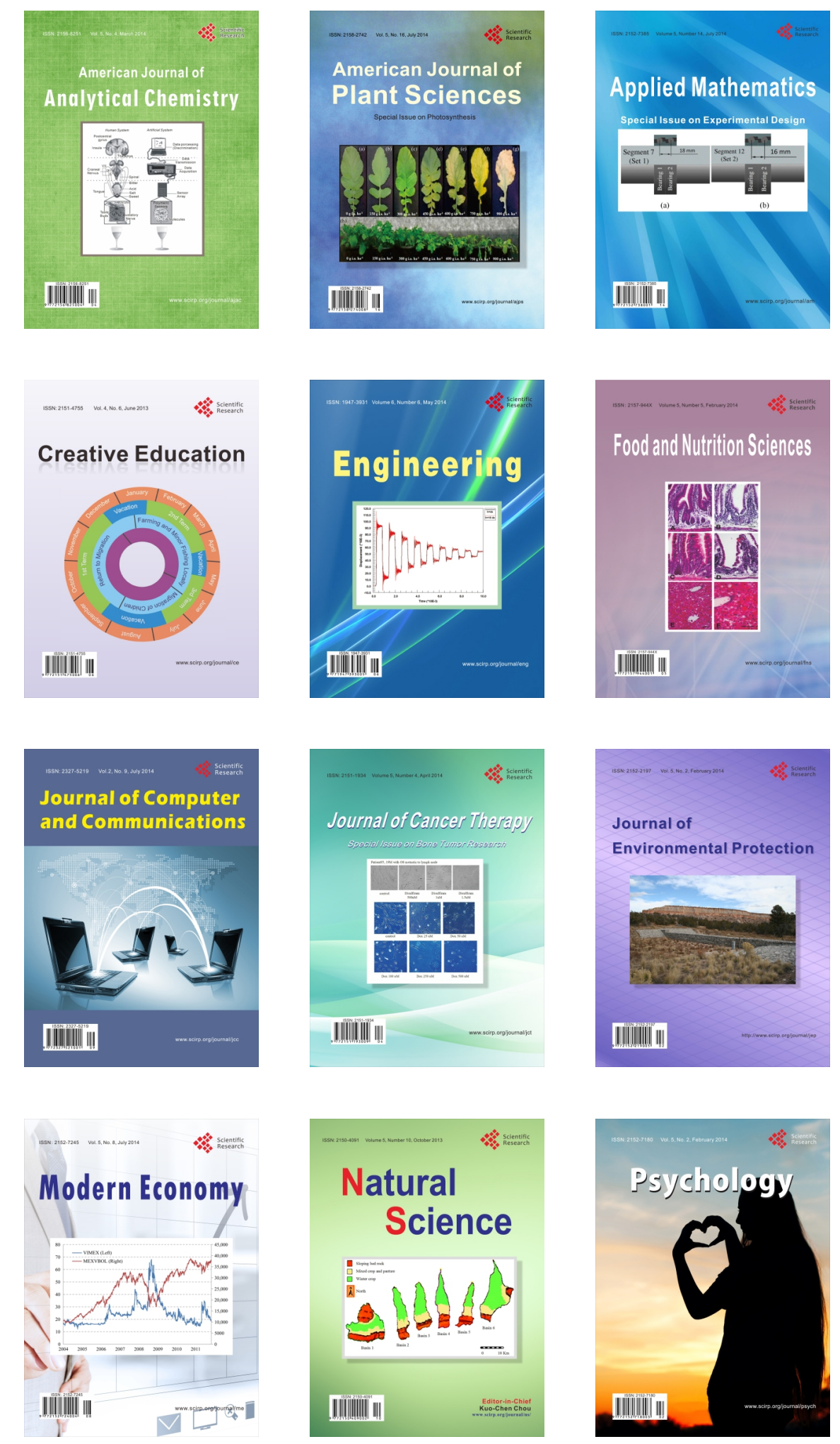